\title{
Selective laser trabeculoplasty reduces mean IOP and IOP variation in normal tension glaucoma patients
}

This article was published in the following Dove Press journal:

Clinical Ophthalmology

29 July 2010

Number of times this article has been viewed

\author{
Mohammed K El Mallah' \\ Molly M Walsh ${ }^{2}$ \\ Sandra S Stinnett ${ }^{2}$ \\ Sanjay G Asrani ${ }^{2}$ \\ 'Ocala Eye, Ocala, Florida, USA; ²Duke \\ University Eye Center, Durham, North \\ Carolina, USA
}

Purpose: To evaluate the effect of selective laser trabeculoplasty (SLT) in normal tension glaucoma (NTG) patients.

Patients and methods: A retrospective review was performed of NTG patients who had undergone SLT at the Duke University Eye Center between 12/2002 and 7/2005. For each eye of each patient at pre-laser and post-laser time points, the IOP measurements were summarized by mean, standard deviation, and range. Then for each of these descriptive statistics, the differences between pre-laser and post-laser values were obtained. Statistical analysis was performed using a random effects model. Main outcome measures: difference in mean IOP, standard deviation of IOP, and range of IOP.

Results: Thirty-one eyes of 18 patients were included for analysis. The average of the mean pre-operative IOP measurements was $14.3 \pm 2.6 \mathrm{mmHg}$ compared to $12.2 \pm 1.7 \mathrm{mmHg}$ $(P<0.001)$ post-operatively. The mean pre-operative standard deviation was $1.9 \pm 0.9 \mathrm{mmHg}$ compared to $1.0 \pm 0.6 \mathrm{mmHg}(P=0.002)$ post-operatively while the mean IOP range prior to treatment was $4.5 \pm 2.5 \mathrm{mmHg}$ compared to $2.5 \pm 1.9 \mathrm{mmHg}(P=0.017)$ after treatment.

Conclusion: In this pilot study, SLT was found to lower mean IOP and intervisit IOP variation in NTG patients. Given the importance of IOP variation and its association with glaucoma progression, measurement of IOP variation following treatment with SLT may be considered.

Keywords: SLT, NTG, laser, glaucoma

\section{Introduction}

Normal tension glaucoma (NTG) was first described in 1857 by von Graefe. ${ }^{1}$ Its diagnosis is based on "characteristic optic nerve head cupping and glaucomatous visual field loss in the absence of a narrowed anterior chamber angle or an IOP above the statistical norm". ${ }^{2}$ Specifically, the intraocular pressure (IOP) never exceeds $21 \mathrm{mmHg} .{ }^{3}$

Several studies, including the Early Manifest Glaucoma Trial, showed that lowering intraocular pressure in primary open angle glaucoma decreases the incidence of glaucoma progression. ${ }^{4}$ Data from the Collaborative Normal Tension Glaucoma Study demonstrated that patients with normal tension glaucoma also have delayed glaucoma progression with intraocular pressure reduction. ${ }^{5}$

IOP fluctuation and variation have also emerged as strong risk factors for glaucoma progression. ${ }^{6-9}$ In a recent study, Lee et $\mathrm{al}^{8}$ found that each unit increase in standard deviation of intervisit IOP resulted in at least a 4-fold increase in the risk of glaucomatous visual field progression. In a NTG cohort, Collaer et $\mathrm{al}^{10}$ found a significant correlation between visual field deterioration and the range of IOP measured during day-long sequential IOP readings.
Correspondence: Mohammed El Mallah Ocala Eye, I 500 SE Magnolia Ext, Suite 106, Ocala, FL 3447I, USA

$\mathrm{Tel}+\mathrm{I} 3526225183$

$\mathrm{Fax}+\mathrm{I} 3526295026$

Email elmallah@post.harvard.edu 
Thus, in both primary open angle glaucoma (POAG) in general and the subgroup of patients with NTG, there is evidence that both reduction of IOP as well as reduction of IOP fluctuation can decrease the incidence of visual field deterioration. A modality commonly used to treat POAG is laser trabeculoplasty. Multiple studies have demonstrated the efficacy of laser trabeculoplasty in lowering IOP in POAG patients. ${ }^{11-14} \mathrm{~A}$ few studies have also demonstrated that laser trabeculoplasty decreases IOP fluctuation in glaucoma patients. ${ }^{15-18}$

We sought to examine the role of selective laser trabeculoplasty (SLT) specifically in normal tension glaucoma patients. Therefore, we designed a study to retrospectively assess the effect of SLT on IOP as well as on IOP variation in NTG patients.

\section{Methods}

This study is a retrospective chart review of NTG patients who had undergone SLT at the Duke University Eye Center between December 2002 and July 2005. Institutional review board approval was obtained to access data in the patient charts.

A search through our billing codes during the above time period was performed for the codes for normal tension glaucoma and SLT. All patients retrieved from this query were included in the study. Patients were excluded from study if they ever manifested an IOP greater than 21 in either eye. Other exclusion criteria were less than three pre-laser or three post-laser visits, prior laser trabeculoplasty or other prior glaucoma surgery.

The Coherent Selecta 7000 laser, a frequency-doubled q-switched neodymium:ytrium-aluminum-garnet laser, had been used to treat these patients. This laser has a wavelength $532 \mathrm{~nm}$ with a pulse duration of 3 nanoseconds and a spot size of $400 \mu \mathrm{m}$. The Ritch trabeculoplasty lens was used with the mirrored thumbnail lens to focus the laser onto the trabecular meshwork. The energy level was initially set at 0.7 millijoules $(\mathrm{mJ})$ and the energy was varied such that at least $50 \%$ of the spots resulted in micro bubble formation. The total amount of delivered energy was recorded.

Postoperative management included one post laser eyedrop each of $1 \%$ prednisolone acetate and of $0.15 \%$ brimonidine. IOP was checked after 45 minutes to ensure the absence of an IOP spike. If the IOP was raised by more than $2 \mathrm{mmHg}$ compared to pre laser IOP, one set of the above two drops were re-instilled and the IOP was rechecked in 30 minutes. Patients were then followed at 5 weeks and subsequently at 3-month intervals. At each of these visits, IOP, medications as well as any complications were recorded.
Patients had multiple IOP measurements in each eye at pre-laser and post-laser time points. For the purposes of this study, only the IOP measurements one year prior and one year after laser were recorded. This one-year period was extended in either direction if there were not three measurements taken during this timeframe.

For each eye of each patient at pre-laser and post-laser time points, the measurements were summarized using the mean, standard deviation, minimum, maximum, and range of values of the multiple assessments of IOP. The range was defined as the difference between the maximum and minimum IOP.

Then for each of these descriptive statistics, for each patient, the differences between pre-laser and post-laser values were obtained. For example, the difference in mean IOP was computed as the mean of IOP measurements at the post-laser time points minus the mean of the IOP measurements at the pre-laser time points. Likewise, the difference in the range of IOP measurements was computed as the range of IOP measurements from the post-laser time points minus the range of IOP measurements from the pre-laser time points.

Once the differences between pre-laser and post-laser values for mean IOP, SD of IOP, minimum IOP, maximum IOP, and range of IOP were computed for each patient, a random effects model to test for statistical significance was applied. In this model, the patient was considered as a random effect to account for the dependence of measurements from two eyes of the same patient.

Further analysis examined the role of possible confounding variables. These included the differences between prelaser and post-laser number of visits, number of medications and number of changes in medications. Specifically, the random effects model was used to test for changes in these variables. In addition, we conducted both univariate as well as multivariate analyses (also using the random effects model) to test whether inclusion of any of these possible confounders altered our results with respect to changes in mean IOP, SD of IOP, and range of IOP. The SAS 9.1 software package (Cary, NC) was used for analysis.

\section{Results}

Thirty-one eyes of 18 normal tension glaucoma patients were included for analysis. The mean age was 61 years (range: 44 to 82 ) and $72 \%$ were female. Four eyes of three patients underwent 180 degrees of treatment while the remaining 27 eyes of 15 patients underwent 360 degrees of treatment with selective laser trabeculoplasty. 
The average of the mean pre-laser IOP measurements was $14.3 \pm 2.6 \mathrm{mmHg}$ while the average of the mean postlaser IOP measurements was $12.2 \pm 1.7 \mathrm{mmHg}(P<0.001)$ (Figure 1). The mean pre-laser IOP standard deviation was $1.9 \pm 0.9 \mathrm{mmHg}$ while the mean standard deviation after laser was $1.0 \pm 0.6 \mathrm{mmHg}(P=0.002)$ (Figure 2). The mean IOP range prior to laser treatment was $4.5 \pm 2.5 \mathrm{mmHg}$. After laser treatment, the mean IOP range decreased to $2.5 \pm 1.9 \mathrm{mmHg}$ $(P=0.017)$ (Figure 3).

The mean maximum IOP decreased from $16.4 \pm 3.0 \mathrm{mmHg}$ prior to treatment to $13.6 \pm 1.7 \mathrm{mmHg}$ after treatment $(P=0.001)$. Before undergoing SLT, the mean minimum IOP recorded was $11.9 \pm 3.0 \mathrm{mmHg}$. The mean minimum IOP recorded after SLT was $11.1 \pm 2.0 \mathrm{mmHg}(P=0.073)$ (Table 1).

There was no significant difference between pre-laser and post-laser values for the number of clinic visits or for the number of medications being used. The mean number of pre-laser visits was $4.8 \pm 1.5$ while the mean number of post-laser visits was $4.9 \pm 2.7(P=0.583)$. The mean number of medications at the time of laser was $1.68 \pm 1.11$ while the mean number of medications at last follow-up was $1.45 \pm 1.18(P=0.178)$.

There was, however, a significant difference in the number of changes in medications before and after laser. The mean number of changes in medication prior to laser was $0.9 \pm 0.9$ while the mean number of changes in medication after laser was $0.4 \pm 0.9(P=0.039)$.

In both univariate and multivariate analyses, inclusion of these variables (number of visits, number of medications,

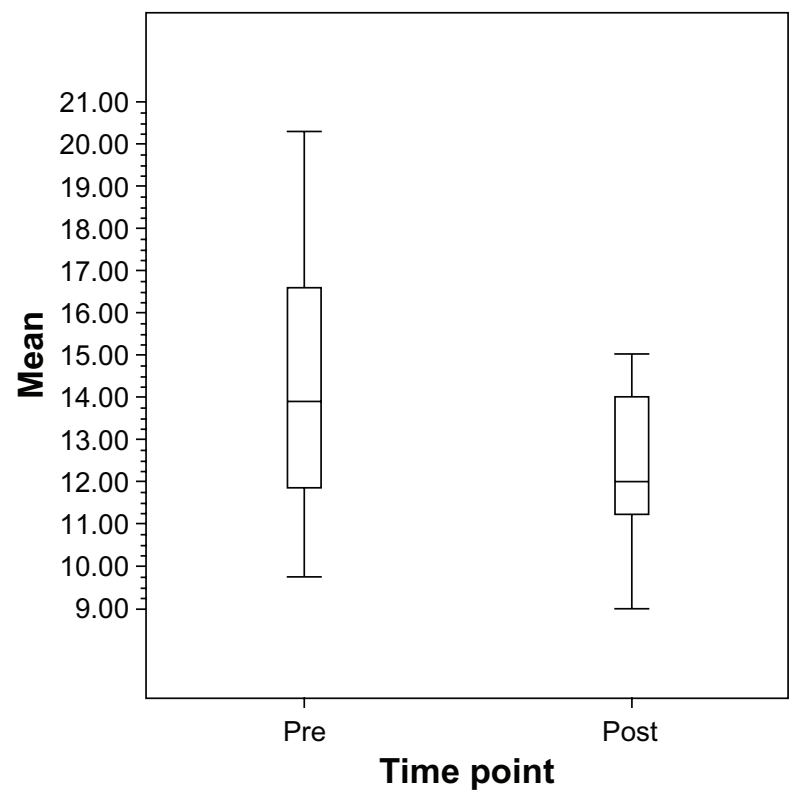

Figure I Boxplot of mean IOP pre-SLT vs post-SLT in NTG patients.

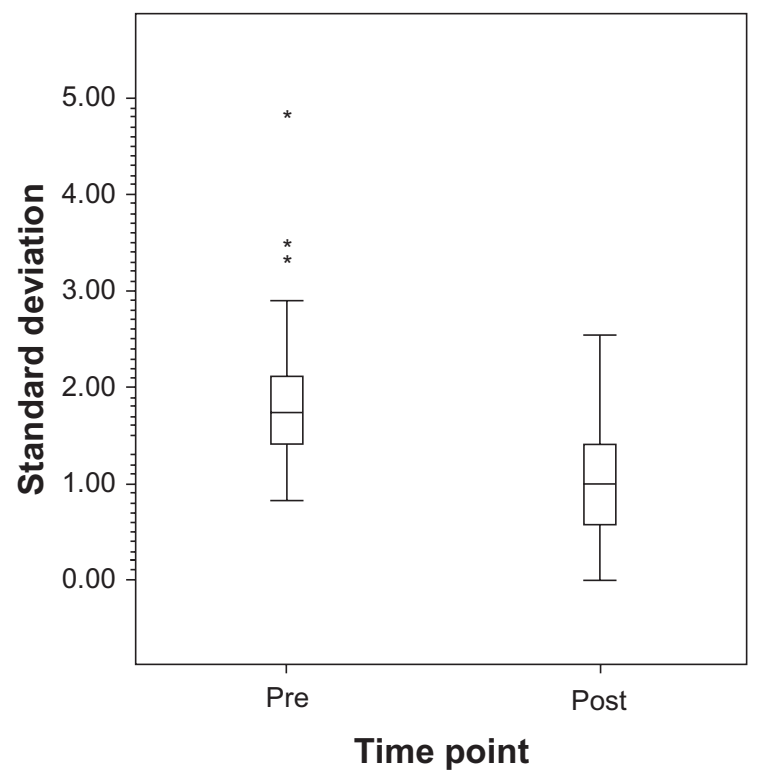

Figure 2 Boxplot of standard deviation pre-SLT vs post-SLT in NTG patients.

and number of changes in medications) did not change the primary outcomes of change in mean IOP, change in SD of IOP, or change in range of IOP. All these changes remained statistically significant (Table 2). The mean duration of prelaser measurements was 7.8 months while the mean duration of post-laser follow-up measurements was 9.9 months. No patient had an adverse event.

\section{Discussion}

In normal tension glaucoma patients, our study showed that selective laser trabeculoplasty reduces mean intraocular

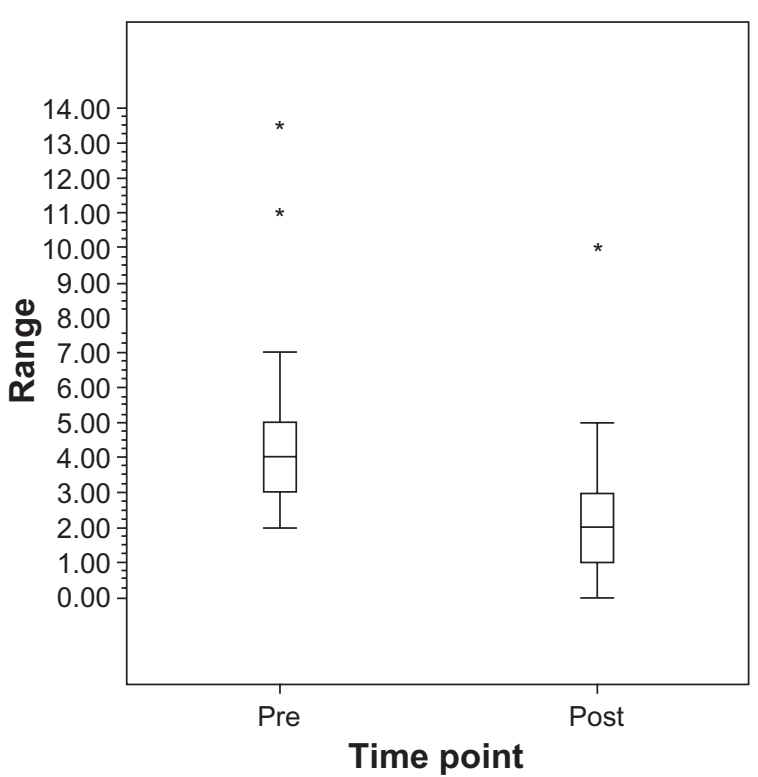

Figure 3 Boxplot of range of IOP pre-SLT and post-SLT in NTG patients. 
Table I IOP measures before and after SLT in NTG patients

\begin{tabular}{lllll}
\hline & $\begin{array}{l}\text { Pre-laser } \\
(\mathbf{m m H g})\end{array}$ & $\begin{array}{l}\text { Post-laser } \\
(\mathbf{m m H g})\end{array}$ & \multicolumn{1}{c}{$\begin{array}{l}\text { Difference } \\
(\mathbf{m m H})\end{array}$} \\
\hline Mean of average IOP & $14.3 \pm 2.6$ & $12.2 \pm 1.7$ & -2.03 & $<0.001$ \\
Mean of standard deviation of IOP & $1.9 \pm 0.9$ & $1.0 \pm 0.6$ & -0.90 & 0.002 \\
Mean of range of IOP & $4.5 \pm 2.5$ & $2.5 \pm 1.9$ & -2.02 & 0.017 \\
Mean of maximum IOP & $16.4 \pm 3.0$ & $13.6 \pm 1.7$ & -2.86 & 0.001 \\
Mean of minimum IOP & $11.9 \pm 3.0$ & $11.1 \pm 2.0$ & -0.84 & 0.073 \\
\hline
\end{tabular}

pressure as well as intraocular pressure intervisit variation as defined both by standard deviation of IOP and IOP range.

In the context of this study, IOP variability can be affected by many variables. Among these are frequent changes in therapy as well as the number of adjunct topical hypotensive drops. Increased number of topical drops could possibly result in decreased fluctuation. Neither inclusion of number of medications nor inclusion of number of changes in medications altered our primary outcome variables. That is, even when number of changes in medications as well as number of medications are included in our multivariate analysis, SLT still decreased IOP variation.

Another possible confounder when measuring variability by standard deviation is that increased number of observations may lower standard deviation. ${ }^{8}$ Once again, in our sample, we found that number of visits had no impact on any of our results.

One previous study has examined the role of argon laser trabeculoplasty (ALT) in normal tension glaucoma patients. ${ }^{19}$ Schwartz et al found that ALT reduced mean IOP as well as peak IOP. There was no comment as to the effect on IOP range or IOP standard deviation. This prior study included patients with previous intraocular pressures above $21 \mathrm{mmHg}$ as well as patients with secondary glaucomas such as pigment dispersion syndrome. We were careful in selecting our exclusion criteria so as to only include patients that met the strictest criteria for normal tension glaucoma.

Table 2 Univariate analyses of possible confounding variables showing no impact on the statistical significance of difference in mean IOP, SD of IOP, and range of IOP

\begin{tabular}{|c|c|c|c|}
\hline \multirow[t]{2}{*}{ Variable included } & \multicolumn{3}{|l|}{$P$-value } \\
\hline & $\begin{array}{l}\text { Difference in } \\
\text { mean IOP }\end{array}$ & $\begin{array}{l}\text { Difference in } \\
\text { SD of IOP }\end{array}$ & $\begin{array}{l}\text { Difference in } \\
\text { range of IOP }\end{array}$ \\
\hline None & $<0.001$ & 0.002 & 0.017 \\
\hline Number of visits & $<0.001$ & 0.002 & 0.004 \\
\hline $\begin{array}{l}\text { Number of } \\
\text { medications }\end{array}$ & $<0.001$ & 0.003 & 0.031 \\
\hline $\begin{array}{l}\text { Number of changes } \\
\text { in medications }\end{array}$ & $<0.001$ & 0.007 & 0.045 \\
\hline
\end{tabular}

Although several studies have demonstrated the importance of IOP fluctuation in glaucoma progression, ${ }^{6-9}$ measurement of IOP fluctuation is still not routinely performed in the clinical setting. One possible reason is a lack of consensus on how to measure IOP fluctuation. Should we measure IOP range, ${ }^{6,9,10,17,18}$ or IOP standard deviation? ${ }^{7,8}$

Surprisingly, Lee et $\mathrm{al}^{8}$ found that increased IOP range was actually protective against glaucoma progression. As they noted, this was likely because the chronological order of low and high readings were not taken into account. It is likely that many patients who were successfully treated had a high range of IOP as they went from a high IOP to a low IOP, thus confusing the data. If we abandon IOP range for standard deviation, we need also to be wary as standard deviation can be affected by the number of observations; too few observations will yield a large standard deviation.

The authors feel that either method is valid provided it is based on an adequate number of observations and is reset after any treatment intervention. Measuring IOP fluctuation allows practitioners another parameter by which to identify patients at risk of glaucoma progression and by which to monitor the effectiveness of their therapy.

Our study is limited by its retrospective nature as well as the relatively small sample size. However, even with this small sample, the results reached statistical significance. Also, many of our patients were using topical medications and although multivariate analysis showed no effect from number of medications or number of medication changes, given the small sample size, topical medication use may have affected IOP variation. However, in this group of patients, the distribution of use of prostaglandins and aqueous suppressants was the same before as well as after the laser.

Our study is also limited by a follow-up period of less than one year. We cannot say for how long SLT will decrease mean IOP and IOP variation in NTG patients. Additionally, the decrease in variability in IOP measurements as a group may not necessarily indicate individual results.

To our knowledge, this is the first report showing that selective laser trabeculoplasty decreased mean IOP as well 
as inter visit IOP variation in this pilot group of normal tension glaucoma patients. Given the importance of IOP variation and its association with glaucoma progression, measurement of IOP variation following treatment with SLT may be considered.

\section{Acknowledgment}

Mohammed El Mallah had full access to all the data in the study and takes responsibility for the integrity of the data and the accuracy of the data analysis.

\section{Disclosure}

No conflicts of interest were declared in relation to this paper.

\section{References}

1. Von Graefe A. Uber die Iridectomie bei Glaucom und uber den glaucomatosen Prozess. Arch Clin Exp Ophthalmol. 1857;3:456-460.

2. Orgul S, Zawinka C, Gugleta K, et al. Therapeutic strategies for normaltension glaucoma. Ophthalmologica. 2005;219(6):317-323.

3. Sturmer J, Meier-Gibbons F. The diagnosis of normal-tension glaucoma. Curr Opin Ophthalmol. 1994;5(2):64-68.

4. Leske MC, Heijl A, Hussein M, et al. Factors for glaucoma progression and the effect of treatment: the early manifest glaucoma trial. Arch Ophthalmol. 2003;121(1):48-56.

5. Collaborative Normal-Tension Glaucoma Study Group. Comparison of glaucomatous progression between untreated patients with normaltension glaucoma and patients with therapeutically reduced intraocular pressures. Am J Ophthalmol. 1998;126(4):487-497.

6. Asrani S, Zeimer R, Wilensky J, et al. Large diurnal fluctuations in intraocular pressure are an independent risk factor in patients with glaucoma. J Glaucoma. 2000;9(2):134-142.
7. Nouri-Mahdavi K, Hoffman D, Coleman AL, et al. Predictive factors for glaucomatous visual field progression in the Advanced Glaucoma Intervention Study. Ophthalmology. 2004;111(9):1627-1635.

8. Lee PP, Walt JW, Rosenblatt LC, et al. Association between intraocular pressure variation and glaucoma progression: data from a United States chart review. Am J Ophthalmol. 2007;144(6):901-907.

9. Oliver JE, Hattenhauer MG, Herman D, et al. Blindness and glaucoma: a comparison of patients progressing to blindness from glaucoma with patients maintaining vision. Am J Ophthalmol. 2002;133(6):764-772.

10. Collaer N, Zeyen T, Caprioli J. Sequential office pressure measurements in the management of glaucoma. J Glaucoma. 2005;14(3):196-200.

11. Glaucoma Laser Trial Research Group. The Glaucoma Laser Trial (GLT) and glaucoma laser trial follow-up study: 7. Results. Am J Ophthalmol. 1995;120(6):718-731.

12. Melamed S, Ben Simon GJ, Levkovitch-Verbin H. Selective laser trabeculoplasty as primary treatment for open-angle glaucoma: a prospective, nonrandomized pilot study. Arch Ophthalmol. 2003;121(7):957-960.

13. Nagar M, Ogunyomade A, O'Brart DP, et al. A randomised, prospective study comparing selective laser trabeculoplasty with latanoprost for the control of intraocular pressure in ocular hypertension and open angle glaucoma. Br J Ophthalmol. 2005;89(11):1413-1417.

14. McIlraith I, Strasfeld M, Colev G, et al. Selective laser trabeculoplasty as initial and adjunctive treatment for open-angle glaucoma. J Glaucoma. 2006;15(2):124-130.

15. Greenidge KC, Spaeth GL, Fiol-Silva Z. Effect of argon laser trabeculoplasty on the glaucomatous diurnal curve. Ophthalmology. 1983;90(7): 800-804.

16. Guzey M, Arslan O, Tamcelik N, et al. Effects of frequency-doubled $\mathrm{Nd}$ :YAG laser trabeculoplasty on diurnal intraocular pressure variations in primary open-angle glaucoma. Ophthalmologica. 1999;213(4):214-218.

17. Agarwal HC, Sihota R, Das C, et al. Role of argon laser trabeculoplasty as primary and secondary therapy in open angle glaucoma in Indian patients. Br J Ophthalmol. 2002;86(7):733-736.

18. Lee AC, Mosaed S, Weinreb RN, et al. Effect of laser trabeculoplasty on nocturnal intraocular pressure in medically treated glaucoma patients. Ophthalmology. 2007;114(4):666-670.

19. Schwartz AL, Perman KI, Whitten M. Argon laser trabeculoplasty in progressive low-tension glaucoma. Ann Ophthalmol. 1984;16(6): $560-562,566$.
Clinical Ophthalmology

\section{Publish your work in this journal}

Clinical Ophthalmology is an international, peer-reviewed journal covering all subspecialties within ophthalmology. Key topics include: Optometry; Visual science; Pharmacology and drug therapy in eye diseases; Basic Sciences; Primary and Secondary eye care; Patient Safety and Quality of Care Improvements. This journal is indexed on

Submit your manuscript here: http://www.dovepress.com/clinical-ophthalmology-journal

\section{Dovepress}

PubMed Central and CAS, and is the official journal of The Society of Clinical Ophthalmology (SCO). The manuscript management system is completely online and includes a very quick and fair peer-review system, which is all easy to use. Visit http://www.dovepress.com/ testimonials.php to read real quotes from published authors. 